Depressive Symptoms and Risk for Sudden Cardiac Death in Stable Coronary Artery Disease

Minna Lahtinen MSc , Antti M. Kiviniemi PhD , M. Juhani Junttila MD , Maria Kääriäinen $\mathrm{PhD}$, Heikki V. Huikuri MD, Mikko P. Tulppo PhD

PII: S0002-9149(18)31178-0

DOI: 10.1016/j.amjcard.2018.05.006

Reference: $\quad$ AJC 23310

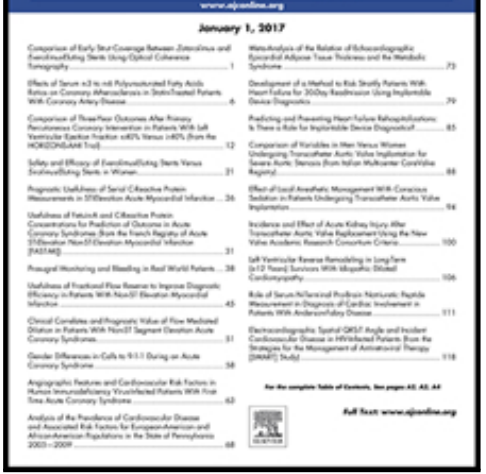

To appear in:

The American Journal of Cardiology

Received date:

26 January 2018

Revised date: $\quad 3$ May 2018

Accepted date: $\quad 7$ May 2018

Please cite this article as: Minna Lahtinen MSc, Antti M. Kiviniemi PhD, M. Juhani Junttila MD , Maria Kääriäinen PhD , Heikki V. Huikuri MD, Mikko P. Tulppo PhD, Depressive Symptoms and Risk for Sudden Cardiac Death in Stable Coronary Artery Disease, The American Journal of Cardiology (2018), doi: 10.1016/j.amjcard.2018.05.006

This is a PDF file of an unedited manuscript that has been accepted for publication. As a service to our customers we are providing this early version of the manuscript. The manuscript will undergo copyediting, typesetting, and review of the resulting proof before it is published in its final form. Please note that during the production process errors may be discovered which could affect the content, and all legal disclaimers that apply to the journal pertain. 
1

\title{
Depressive Symptoms and Risk for Sudden Cardiac Death in Stable Coronary Artery
}

\section{Disease}

Running head: Depression and sudden cardiac death

Minna Lahtinen, $\mathrm{MSc}^{\mathrm{a}, \mathrm{b}}$, Antti M. Kiviniemi, $\mathrm{PhD}^{\mathrm{a}}$, M. Juhani Junttila, MD ${ }^{\mathrm{a}}$, Maria Kääriäinen, $\mathrm{PhD}^{\mathrm{b}}$, Heikki V. Huikuri, $\mathrm{MD}^{\mathrm{a}}$, Mikko P. Tulppo, $\mathrm{PhD}^{\mathrm{a}}$

${ }^{\text {a }}$ Research Unit of Internal Medicine, Medical Research Center Oulu, Oulu University Hospital and University of Oulu, Oulu, Finland

${ }^{\mathrm{b}}$ Research Unit of Nursing Science and Health Management, University of Oulu, Oulu, Finland

Corresponding author: Mikko P. Tulppo, $\mathrm{PhD}$, Research Unit of Internal Medicine, Medical Research Center Oulu, P.O. Box 5000, 90014 University of Oulu, Oulu, Finland, email: mikko.tulppo@oulu.fi, tel: +358 8315 4689, Fax +358 83154774

\begin{abstract}
The association between the mode of death and depression in patients with stable coronary artery disease $(\mathrm{CAD})$ is far from clear. We investigated the association between depressive symptoms
\end{abstract}


and the mode of death including all-cause mortality, non-cardiac death, sudden cardiac death (SCD) and non-SCD in stable CAD patients. Patients with angiographically documented CAD $(\mathrm{n}=1,928)$ underwent a clinical examination including screening for depression symptoms with the Depression Scale (DEPS) and extensive risk profiling at the baseline. The patients were divided into quartiles based on their DEPS score. The patients entered the follow-up (median 6.3 years) during which $49 \operatorname{SCDs}(2.5 \%)$ and 48 non-SCDs (2.5\%) occurred. The incidence of SCD was $1.1 \%$ (5 events), $2.0 \%$ (9 events), $2.6 \%$ (14 events) and $4.4 \%$ (21 eyents) from the lowest to the highest quartile of DEPS. The patients in the highest quartile of DEPS had a 4.0-fold elevated univariate risk (95\% CI: 1.5-10.5; $\mathrm{p}=0.006$ ), and after adjustment for traditional risk factors, a 3.2-fold elevated multivariate risk (95\% CI: 1.2-8.9, $\mathrm{p}=0.025)$ for SCD compared to patients in the lowest quartile. DEPS was not associated with non-SCD or non-cardiac deaths. Depressive symptoms are associated with an increased risk of SCD independently of clinical risk factors in patients with CAD. The results highlight the importance of screening for depression and emphasize the need for additional interventions to alleviate the depressive symptoms in these patients.

Keywords: Ischemic heart disease; mental wellbeing; sudden cardiac death

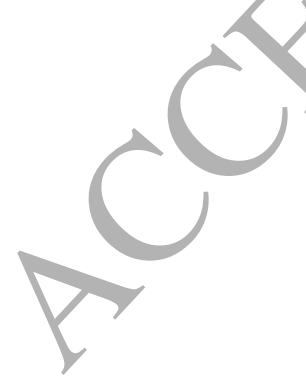

Patients with coronary artery disease (CAD) often suffer from clinical depression or depressive symptoms. Several recent studies have estimated that approximately $20-45 \%$ of patients with CAD experienced clinical depression or depressive symptoms compared to the rate 
of about $4 \%$ in the general population ${ }^{1}$. There is convincing evidence that depression is an independent risk factor for a poor prognosis among cardiac patients and the elderly population ${ }^{1,2}$. In particular, depression may be associated with cardiac death and non-fatal cardiac events after an acute coronary syndrome ${ }^{1}$. However, the association between depression and a specific form of cardiac death, i.e. sudden cardiac death (SCD) vs. non-SCD, is not known among CAD patients. We hypothesized that depression symptoms may be associated with cardiac mortality independently of traditional risk markers including left ventricular function and life style factors and tested this hypothesis in a consecutive series of stable CAD patients attending Oulu University Hospital at 2007-2014. We analyzed the association between depressive symptoms and all-cause mortality, non-cardiac death, non-SCD and SCD adjusted with appropriate risk markers.

\section{Methods}

The study population comprised 1,928 patients from the ARTEMIS (Innovation to Reduce Cardiovascular Complications of Diabetes at the Intersection, ClinicalTrials.gov identifier: NCT01426685) study database ( $n=1,946$, none lost cases during follow-up) collected in the Division of Cardiology of the Oulu University Hospital (Oulu, Finland). The ARTEMIS study aims to assess several traditional and novel cardiovascular risk markers as determinants of risk for SCD in patients with stable CAD. The patients were recruited from a consecutive series of patients who had undergone coronary angiography 3-6 months earlier and had > 3 months from any possible previous acute coronary syndrome before enrollment. Significant CAD was confirmed by coronary angiography (stenosis > 50\%) and type 2 diabetes (DM2) according to the WHO criteria. Detailed inclusion and exclusion criteria have been described elsewhere in detail ${ }^{3}$. Shortly, patients with age $<18$ years or $>85$ years, New York Heart Association class IV, a 
permanent pacemaker or implantable cardioverter defibrillator, planned implantable cardioverter defibrillator implantation, or end-stage renal failure needing dialysis were excluded from this study, as well as patients who had a life expectancy of $<1$ year due to the severe other disease. The study was performed according to the Declaration of Helsinki, and the local committee of research ethics of the Northern Ostrobothnia Hospital District approved the protocol and all the subjects provided written informed consent.

The patients filled in a self-rating Depression Scale (DEPS) ${ }^{4}$ during the enrolment visit. DEPS has been developed and validated in primary care patients. It is known that DEPS improves the recognition of depression and is also suitable for screening depression in the general population and for identifying high-risk groups ${ }^{5}$. The DEPS questionnaire contains ten items and each item is scored from 0 to 3 in increasing order of severity. A sum of DEPS score was calculated and the patients were divided into quartiles based on the score obtained $(<2,2-4,5-7$, $\geq 8$ ). In earlier studies, the cut-off point for depression has been $\geq 8$ points showing the sensitivity for depression 74-95 \% with a specificity for non-depression of $85-74 \%{ }^{5,6}$. The association between end-points and total DEPS score was calculated and the analyses were also performed for the individual items in the DEPS. The characteristics of patients according to DEPS score quartiles are shown in table 1 with the specific answers in DEPS described in table 2.

The patients filled in a health questionnaire containing a answer about the frequency of habitual leisure time physical activity (LTPA), smoking status and alcohol consumption during the enrolment visit. Four LTPA groups were formed by modifying the scale originally developed by Saltin and Grimby ${ }^{7}$ : 1) Inactive; 2) Irregularly active; 3) Active, moderate-intensity LTPA regularly two to three times weekly; 4) Highly active, moderate- or high-intensity LTPA more than three times weekly ${ }^{8}$. The questionnaire has demonstrated good validity ${ }^{9}$ and has been shown to be related to both cardiovascular risk factors ${ }^{9,10}$ and outcomes ${ }^{8}$. 
Fasting venous blood samples and urine samples were obtained for the analysis of renal function, blood lipids, plasma glucose, and glycated haemoglobin (HbA1c) levels. Those subjects without previously diagnosed DM2 underwent an oral glucose tolerance test to establish their glucose metabolism status. Blood pressure was measured in a supine position after a 10-min resting period. Two-dimensional, M-mode and tissue Doppler echocardiography was performed utilizing the same ultrasound machine in all of the patients (Vivid 7, GE Healthcare, Wauwatosa, WI). Left ventricular mass index and left ventricular ejection fraction (LVEF) were measured by the biplane method from 2- and 4-chamber views. The SYNTAX Score was calculated by three experienced interventional cardiologists after revascularization operation condition using the Web-based calculator version 2.11 on SYNTAX Score Web site (http://www.syntaxscore.com).

Deaths were defined as SCD, non-SCD and non-cardiac deaths. In addition, resuscitations from cardiac arrest were registered and combined with deaths, SCDs and cardiac deaths in statistical analyses, the aborted SCD being the primary event if patient died during the follow-up. The primary endpoint of this study was SCD including resuscitations from cardiac arrest. The follow-up information was collected from the national death registries, from patients by mailed inquiry, telephone calls to the closest relatives of the deceased victims, and from the electronic patient records. SCD was defined as unexpected, witnessed death occurring within one hour after the onset of symptoms or unwitnessed death within 24 hours when the patient was last seen alive. The cause of death was defined by an endpoint committee (MJJ, HVH) based on the death certificates, interviews with the closest relatives of victims and the autopsy reports. A medicolegal autopsy is mandatory in Finland according to the law and thus autopsy data was available in most cases.

In the Artemis study, we expected 5\% and 2\% incidence of SCD in the patients with and without type 2 diabetes during 5-year follow-up, respectively. With statistical power of $80 \%$ and 
$\alpha$ level of $5 \%$, at least 584 patients were needed per group. Retrospectively in the present study, the incidences of SCD in the 1st quartile of DEPS (1.1\%) and the 4th quartile (4.4\%), sample size and $\alpha$ level provided statistical power of $86 \%$. The between-group differences were assessed by one-way ANOVA, Kruskal-Wallis or chi-squared followed by post hoc analyses by Bonferroni, Mann-Whitney U-test or chi-squared adjusted for multiple comparisons. To study the association between depressive symptoms and a the mode of death, DEPS score and individual DEPS answers were assessed by Receiving Operating Characteristic (ROC) and univariate Cox regression followed by adjustment for age, sex, body mass index, DM2, left ventricular ejection fraction, Canadian Cardiovascular Society grading of angina pectoris (CCS class), use of psychotropic medication and LTPA. Cox regression analysis was performed also excluding patients receiving psychotropic medication and separately excluding psychotropic medication with known propensity for QT-prolongation ${ }^{11}$. Kaplan-Meier analysis was used to illustrate survival curves of different groups of risk. The data were analyzed using SPSS software (IBM SPSS Statistics 21, IBM Corp., New York, USA). A p-value <0.05 was considered as statistically significant.

\section{Results}

All cause-mortality was $10.5 \%$ (202 events) during the median follow-up of 6.3 years (min - max: $2.2-9.0$ years in survivors). The incidence of cardiac deaths was $5.0 \%$ (97 events) including 2.5\% SCDs (49 events) and $2.5 \%$ non-SCDs (48 events). The incidence of noncardiac deaths was $5.4 \%$ (105 events). All cause-mortality, cardiac deaths and SCDs included 8 aborted SCDs of whom, 2 suffered SCD and 2 had a non-SCD, whereas the other four remained alive during the follow-up. 
The characteristics of patients in different DEPS quartiles are shown in table 1. The incidence of all cause-mortality and SCDs were significantly more frequent among the highest quartile of DEPS score (Table 1). However, there were no differences in non-cardiac deaths or non-SCDs among different DEPS quartiles. The distribution of individual answers in the DEPS in the SCDs and in the living patients as well as all deaths except SCD patients are shown in table 2. The most significant individual answer in DEPS associating with SCD was: "Felt that everything was an effort" (Table 2).

Cox regression analysis for total DEPS score and the most powerful individual answers of DEPS for SCD and all cause-mortality are shown in table 3. Those patients in the highest quartile of DEPS score had 4.0-fold ( $\mathrm{p}=0.006), 2.3$-fold $(\mathrm{p}=0.036)$ and 1.7-fold $(\mathrm{p}=0.107)$ univariate risk for SCD as compared to patients in the lowest, $2^{\text {nd }}$ and $3^{\text {rd }}$ quartile, respectively (Table 3 ). After adjustments for age, sex, body mass index, DM2, left ventricular ejection fraction, CCS class, use of psychotropic medication and LTPA, the patients in the highest quartile of DEPS score still displayed a 3.2-fold risk $(\mathrm{p}=0.025)$ for SCD compared to the patients in the lowest and with a tendency also when compared to the $2^{\text {nd }}$ quartile i.e. a 2.2-fold risk $(\mathrm{p}=0.074)$. Kaplan-Meier survival curves of the risk groups according to their Depression Scale Score for SCD and nonsudden cardiac death are shown in figure 1.

Among individual answers, "Felt that everything was an effort" showed the strongest association, exhibiting a 3.6-fold univariate $(\mathrm{p}=0.001)$ and 3.5 -fold $(\mathrm{p}=0.003)$ adjusted risk for SCD. The univariate or multivariate risk of DEPS for SCD did not change when the analysis was performed excluding patients receiving psychotropic medication (hazard ratio 4.0; $95 \%$ CI: 1.5 10.5, $\mathrm{p}<0.01$ and 3.2; $95 \% \mathrm{CI}: 1.2-8.9 ; \mathrm{p}<0.05$, for univariate and multivariate risks, respectively) or psychotropic medication with known propensity for QT-prolongation (hazard ratio 3.6; $95 \% \mathrm{CI}$ : 1.3-9.8, $\mathrm{p}<0.05$ and $2.9 ; 95 \% \mathrm{CI}$ : $1.1-8.0 ; \mathrm{p}<0.05$, for univariate and 
multivariate risks, respectively). Finally, the changes in medication during follow-up were not associated with the severity of depression or the occurrence of SCD.

\section{Discussion}

The main finding of this study is that depressive symptoms are associated with the increase risk for SCD, but not for non-SCD or non-cardiac death, in patients with stable CAD in the current medical and revascularization era. This finding remained unchanged even after adjustment for traditional clinical risk markers including left ventricular function, psychotropic medication with or without known propensity for QT-prolongation and life style risk factors. The present results emphasize the importance of screening for depression in patients with stable CAD and indicate that additional interventions should be undertaken to alleviate the depressive symptoms among these patients.

The association between depression, non-SCD and SCD has been investigated in four earlier studies. Irvine et al. found that depressive symptoms were associated with SCD in myocardial infarction patients but the association was not significant after adjustment for somatic symptoms such as subjective fatigue ${ }^{12}$. The data were collected two decades ago and left ventricular ejection fraction was not used as a covariate. In the three other studies, clinical depression or depressive symptoms have been shown to associated with SDCs in a cohort of elderly men and woman ${ }^{2}$, in a population based case-control study ${ }^{13}$ and in a large cohort of women without coronary heart disease at baseline ${ }^{14}$. In all these studies, depressive symptoms remained as an independent risk factor for SCD after adjustment with traditional risk markers.

It is well known that the risk of SCD rises dramatically in conjunction with the number of coronary heart diseases risk factors. Major advances have been made in rapid revascularization during and after myocardial infarction in the last decade, and optimization of medical therapy 
among CAD patients has improved the prognosis of patients with CAD ${ }^{15}$. Therefore, there is a lack of knowledge concerning the association between depressive symptoms and the mode of death in the current treatment era in patients with a known CAD. The present findings could help to target health care resources more effectively to selected patients groups among CAD patients in order to prevent SCDs. The most powerful predictor for SCD was the answer "Felt that everything was an effort" revealing 3.5 fold risk for SCD in multivariate analysis. In the earlier validation study, the same answer has been the best item for recognizing depression, suggests reduction of energy, which is one of the main symptoms of depression according to the ICD-10 ${ }^{6}$.

A lack of physical activity was the most powerful predictor of SCDs of the traditional covariates when analyzed without inclusion of the DEPS scale. The most passive group had a 2.9 fold increased risk for SCDs compared with the active group who performed moderate-intensity exercise regularly two to three times weekly. In addition, the most active group, performing moderate- or high-intensity exercise more than three times weekly, tended to have increased risk for SCDs compared with the active group (moderate-intensity LTPA regularly two to three times weekly). Recently, a reverse J-shaped association has been documented between vigorous physical activity and cardiovascular mortality ${ }^{16}$. Both inactive and daily active patients displayed increased hazards of mortality compared to the reference group, in this trial, patients who were active two to four times per week ${ }^{16}$. Furthermore, it is rather well documented that exercise increases the risk of ventricular arrhythmias and sudden cardiac death during or after exertion, particularly in adults with heart disease; our results support these published reports ${ }^{17,18}$.

Based on the present study, we can only speculate about the physiological mechanisms linking depression and SCDs. First, some psychotropic medication with known propensity for QT-prolongation have been reported to increase vulnerability to cardiac arrhythmic events, particularly in women ${ }^{14}$. However, removal of patients being administered psychotropic 
medication without or with known propensity for QT-prolongation did not change the main results and therefore psychotropic medication does not seem to explain the association between depression symptoms and SCDs in the present study. Altered autonomic regulation is one potential mechanism leading to an increased prevalence on SCDs among depressive CAD patients. Augmented sympathetic activity and/or attenuated cardiac vagal activity have been shown to be associated with cardiac events among large CAD patient populations ${ }^{19-21}$. Furthermore, previous studies have observed abnormalities in autonomic/regulation as documented by the heart rate variability method in CAD patients, with depression ${ }^{22}$. Unfortunately, convincing mechanisms linking SCDs and depression symptoms remain to be revealed. The triggering mechanism may not be one single physiological regulatory system but rather complex cascades of various harmful environmental (stress, eating habits, heat, cold etc.) and physiological factors.

This study did not include a clinical depression diagnosis. The DEPS scale has been validated only for screening purposes of depression in primary care patients; it identifies a depressed mood, but not the severity of depression ${ }^{4}$. Therefore, we are not able to make a statement about the possible association between the severity of clinical depression and cardiac events in CAD patients, despite the clear linear association between the depression symptoms and increased risk for SCD emerging from our data. Secondly, a large patient population with more clinical endpoints would be needed to confirm the link between the severity of depression symptoms/clinical depression and cardiac events. However, the sensitivity of DEPS scale for severe depression is rather high (84\%) as is its specificity for symptom-free patients (93\%) which highlights the validity of the found association between depression and SCDs ${ }^{5}$. 
CAD patients suffering depression have an increased risk for SCD in the current medical care era. More attention should be paid to the evaluation and treatment of CAD patients with depression. 


\section{Acknowledgments}

The authors gratefully acknowledge the assistance of the registered nurses Pirkko Huikuri,

Päivi Koski, Päivi Kastell and Sari Kaarlenkaski. Funded by the Finnish Technology Development Center (TEKES) Helsinki, Finland, the Academy of Finland (\#267435), Helsinki, Finland, and the Sigrid Juselius Foundation, Helsinki, Finland.

Declaration of interest: The authors report no conflicts of interest. 


\section{References}

1. Lichtman JH, Froelicher ES, Blumenthal JA, Carney RM, Doering LV, Frasure-Smith N, Freedland KE, Jaffe AS, Leifheit-Limson EC, Sheps DS, Vaccarino V, Wulsin L, American Heart Association Statistics Committee of the Council on E, Prevention, the Council on C, Stroke $\mathrm{N}$. Depression as a risk factor for poor prognosis among patients with acute coronary syndrome: systematic review and recommendations: a scientific statement from the American Heart Association. Circulation 2014;129:1350-1369.

2. Luukinen H, Laippala P, Huikuri HV. Depressive symptoms and the risk of sudden cardiac death among the elderly. Eur Heart J 2003;24:2021-2026.

3. Karjalainen JJ, Kiviniemi AM, Hautala AJ, Piira OP, Lepojarvi ES, Peltola MA, Ukkola OH, Hedberg PS, Huikuri HV, Tulppo MP. Determinants and prognostic value of cardiovascular autonomic function in coronary artery disease patients with and without type 2 diabetes. Diabetes Care 2014;37:286-294.

4. Salokangas RK, Poutanen O, Stengard E. Screening for depression in primary care. Development and validation of the Depression Scale, a screening instrument for depression. Acta Psychiatr Scand 1995;92:10-16.

5. Poutanen O, Koivisto AM, Kaaria S, Salokangas RK. The validity of the Depression Scale (DEPS) to assess the severity of depression in primary care patients. Fam Pract 2010;27:527534.

6. Poutanen O, Koivisto AM, Joukamaa M, Mattila A, Salokangas RK. The Depression Scale as a screening instrument for a subsequent depressive episode in primary healthcare patients. $\mathrm{Br} J$ Psychiatry 2007;191:50-54. 
7. Saltin B, Grimby G. Physiological analysis of middle-aged and old former athletes. Comparison with still active athletes of the same ages. Circulation 1968;38:1104-1115.

8. Karjalainen JJ, Kiviniemi AM, Hautala AJ, Piira OP, Lepojarvi ES, Perkiomaki JS, Junttila MJ, Huikuri HV, Tulppo MP. Effects of physical activity and exercise training on cardiovascular risk in coronary artery disease patients with and without type 2 diabetes. Diabetes Care 2015;38:706-715.

9. Aires N, Selmer R, Thelle D. The validity of self-reported leisure time physical activity, and its relationship to serum cholesterol, blood pressure and body mass index. A population based study of 332,182 men and women aged 40-42 years. Eur J Epidemiol 2003;18:479-485.

10. Rodjer L, Jonsdottir IH, Rosengren A, Bjorck L, Grimby G, Thelle DS, Lappas G, Borjesson M. Self-reported leisure time physical activity: a useful assessment tool in everyday health care. BMC Public Health 2012;12:693.

11. Woosley RL, Heise CW, Romero KA. QTdrugs List. www.CredibleMeds.org: AZCERT, Inc., Oro Valley, AZ.

12. Irvine J, Basinski A, Baker B, Jandciu S, Paquette M, Cairns J, Connolly S, Roberts R, Gent M, Dorian P. Depression and risk of sudden cardiac death after acute myocardial infarction: testing for the confounding effects of fatigue. Psychosom Med 1999;61:729-737.

13. Empana JP, Jouven X, Lemaitre RN, Sotoodehnia N, Rea T, Raghunathan TE, Simon G, Siscovick DS. Clinical depression and risk of out-of-hospital cardiac arrest. Arch Intern Med 2006;166:195-200.

14. Whang W, Kubzansky LD, Kawachi I, Rexrode KM, Kroenke CH, Glynn RJ, Garan H, Albert CM. Depression and risk of sudden cardiac death and coronary heart disease in women: results from the Nurses' Health Study. J Am Coll Cardiol 2009;53:950-958. 
15. Piironen M, Ukkola O, Huikuri H, Havulinna AS, Koukkunen H, Mustonen J, Ketonen M, Lehto S, Airaksinen J, Antero Kesaniemi Y, Salomaa V. Trends in long-term prognosis after acute coronary syndrome. Eur J Prev Cardiol 2017;24:274-280.

16. Mons U, Hahmann H, Brenner H. A reverse J-shaped association of leisure time physical activity with prognosis in patients with stable coronary heart disease: evidence from a large cohort with repeated measurements. Heart 2014;100:1043-1049.

17. Thompson PD, Franklin BA, Balady GJ, Blair SN, Corrado D, Estes NA, 3rd, Fulton JE, Gordon NF, Haskell WL, Link MS, Maron BJ, Mittleman MA, Pelliccia A, Wenger NK, Willich SN, Costa F, American Heart Association Council on Nutrition PA, Metabolism, American Heart Association Council on Clinical C, American College of Sports M. Exercise and acute cardiovascular events placing the risks into perspective: a scientific statement from the American Heart Association Council on Nutrition, Physical Activity, and Metabolism and the Council on Clinical Cardiology. Circulation 2007;115:2358-2368.

18. Marijon E, Tafflet M, Celermajer DS, Dumas F, Perier MC, Mustafic H, Toussaint JF, Desnos M, Rieu M, Benameur N, Le Heuzey JY, Empana JP, Jouven X. Sports-related sudden death in the general population. Circulation 2011;124:672-681.

19. Schwartz PJ, Yanoli E, Stramba-Badiale M, De Ferrari GM, Billman GE, Foreman RD. Autonomic mechanisms and sudden death. New insights from analysis of baroreceptor reflexes in conscious dogs with and without a myocardial infarction. Circulation 1988;78:969-979.

20. Huikuri HV, Valkama JO, Airaksinen KE, Seppänen T, Kessler KM, Takkunen JT, Myerburg RJ. Frequency domain measures of heart rate variability before the onset of nonsustained and sustained ventricular tachycardia in patients with coronary artery disease. Circulation $1993 ; 87: 1220-1228$. 
21. Huikuri HV, Seppänen T, Koistinen MJ, Airaksinen J, Ikäheimo MJ, Castellanos A, Myerburg RJ. Abnormalities in beat-to-beat dynamics of heart rate before the spontaneous onset of life-threatening ventricular tachyarrhythmias in patients with prior myocardial infarction. Circulation 1996;93:1836-1844.

22. Carney RM, Blumenthal JA, Stein PK, Watkins L, Catellier D, Berkman LF, Czajkowski SM, O'Connor C, Stone PH, Freedland KE. Depression, heart rate variability, and acute myocardial infarction. Circulation 2001;104:2024-2028.

\section{FIGURE LEGENDS}
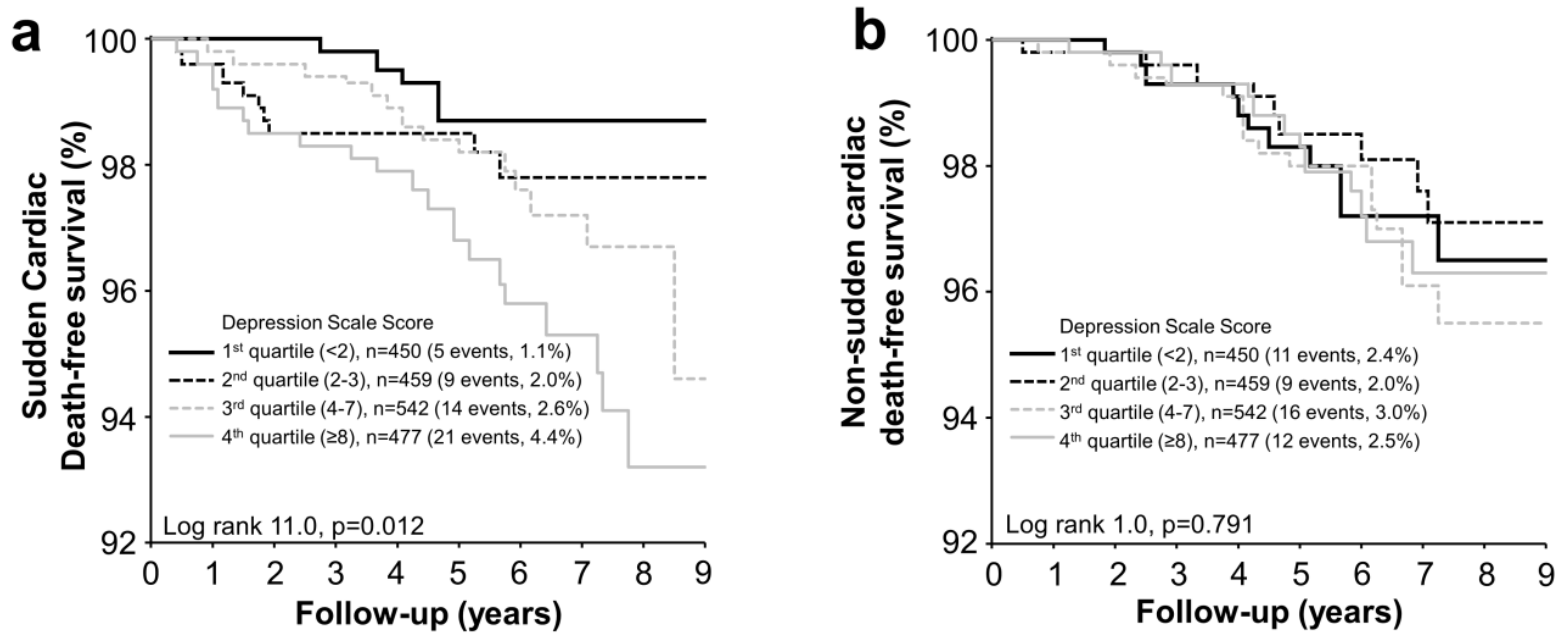

Figure 1. Kaplan-Meier survival curves of the risk groups according to their Depression Scale Score for sudden cardiac (a) and non-sudden cardiac death (b). 
Table 1. Characteristics of patients according to Depression Scale Score quartiles.

\section{DEPS Quartile}

\begin{tabular}{|c|c|c|c|c|}
\hline Variable & $\begin{array}{c}1^{\text {st }} \\
(n=450)\end{array}$ & $\begin{array}{c}2^{\text {nd }} \\
(n=459)\end{array}$ & $\begin{array}{c}3^{\text {rd }} \\
(n=542)\end{array}$ & $\begin{array}{c}4^{\text {th }} \\
(n=477)\end{array}$ \\
\hline \multicolumn{5}{|l|}{ Baseline } \\
\hline Age (years) & $66(9)$ & $67(8)$ & $67(9)$ & $66(9)$ \\
\hline Men $^{\S}$ & $359(80 \%)$ & $326(71 \%)^{*}$ & $340(63 \%) * \dagger$ & $293(61 \%)^{*} \dagger$ \\
\hline Body mass index $\left(\mathrm{Kg} / \mathrm{m}^{2}\right)^{\S}$ & $27(4)$ & $28(4)^{*}$ & $29(5)^{*}$ & $29(5)^{* \dagger}$ \\
\hline $\begin{array}{l}\text { Resting systolic blood pressure } \\
(\mathrm{mmHg})\end{array}$ & $147(26)$ & $148(23)$ & $148(25)$ & $145(25)$ \\
\hline $\begin{array}{l}\text { Resting diastolic blood pressure } \\
(\mathrm{mmHg})\end{array}$ & $81(12)$ & & 12) & $80(11)$ \\
\hline $\begin{array}{l}\text { History of acute myocardial } \\
\text { infarction }\end{array}$ & $231(51 \%)$ & & $251(46 \%)$ & $224(47 \%)$ \\
\hline History of revascularization & $367(82 \%)$ & $359(79 \%)$ & $423(78 \%)$ & $382(80 \%)$ \\
\hline CCS class $\geq 2^{\S}$ & $118(27 \%)$ & $171(38 \%)^{*}$ & $267(50 \%)^{*} \dagger$ & $267(57 \%)^{* \dagger}$ \\
\hline Syntax Score & $0(0-5)$ & $0(0-5)$ & $2(0-6)$ & $0(0-5)$ \\
\hline Diabetes mellitus $\S$ & $155(34 \%)$ & $186(41 \%)$ & $244(45 \%)^{*}$ & $245(51 \%)^{* \dagger}$ \\
\hline Duration of diabetes (years) & $5(1-10)$ & $7(2-13)$ & $5(1-12)$ & $6(2-14)$ \\
\hline $\begin{array}{l}\text { Left ventricular ejection fraction } \\
(\%)\end{array}$ & $64(9)$ & $64(9)$ & $64(9)$ & $65(10)$ \\
\hline $\begin{array}{l}\text { Left ventricular mass } \\
\left(\mathrm{g} / \mathrm{m}^{2}\right)\end{array}$ & 5) & $108(27)$ & $108(27)$ & $106(29)$ \\
\hline $\mathrm{E} / \mathrm{e}^{8}$ & $.5)$ & $10.6(3.9)$ & $11.0(3.9)^{*}$ & $10.9(3.9)^{*}$ \\
\hline $\begin{array}{l}\text { Glycated } \\
(\mathrm{mmol} / \mathrm{mol})^{\S}\end{array}$ & $44.5(10.8)$ & $45.6(11.2)$ & $46.2(11.3)$ & $47.1(11.7)^{*}$ \\
\hline Total cholesterol ( $\mathrm{mmol} / \mathrm{L})$ & $3.92(0.82)$ & $4.03(0.95)$ & $4.02(0.86)$ & $3.98(0.88)$ \\
\hline$(\mathrm{mg} / \mathrm{dL})$ & $151.4(31.6)$ & $155.6(30.7)$ & $155.2(33.2)$ & $153.7(34.0)$ \\
\hline $\begin{array}{l}\text { High-density lipoprotein } \\
\text { cholesterol }(\mathrm{mmol} / \mathrm{L})\end{array}$ & $1.26(0.31)$ & $1.28(0.32)$ & $1.26(0.30)$ & $1.26(0.34)$ \\
\hline$(\mathrm{mg} / \mathrm{dL})$ & $48.7(12.0)$ & $49.8(12.4)$ & $48.7(11.6)$ & $48.7(13.1)$ \\
\hline $\begin{array}{l}\text { Low-density lipoprotein } \\
\text { cholesterol }(\mathrm{mmol} / \mathrm{L})\end{array}$ & $2.26(0.74)$ & $2.31(0.84)$ & $2.31(0.75)$ & $2.27(0.76)$ \\
\hline$(\mathrm{mg} / \mathrm{dL})$ & $87.3(28.6)$ & $89.2(32.4)$ & $89.2(28.9)$ & $87.6(29.3)$ \\
\hline Triglycerides $(\mathrm{mmol} / \mathrm{L})^{\S}$ & $1.1(0.9-1.5)$ & $1.2(0.9-1.7)$ & $\begin{array}{l}1.2(0.9- \\
1.7)^{*}\end{array}$ & $1.3(0.9-1.8)^{*}$ \\
\hline$(\mathrm{mg} / \mathrm{dL})$ & $\begin{array}{c}100.9(75.2- \\
136.3)\end{array}$ & $\begin{array}{c}104.4(79.7- \\
147.8)\end{array}$ & $\begin{array}{c}107.9(81.8- \\
150.4)\end{array}$ & $\begin{array}{c}114.2(83.2- \\
156.2)\end{array}$ \\
\hline Creatinine clearar & $93(31)$ & $93(34)$ & $92(36)$ & $97(35)$ \\
\hline U-Albumin/Creatinine-ratio ${ }^{\S}$ & $0.8(0.5-1.4)$ & $0.8(0.5-1.3)$ & $0.9(0.6-$ & $0.9(0.6-1.6)^{*}$ \\
\hline
\end{tabular}


Lifestyle and medication

Leisure time physical activity ${ }^{\S}$

Highly active

Smokers

Alcohol consumers

Servings/week (if user)

$\beta$-blockers

ACE inhibitors or ATII blockers

Calcium channel blockers

Diuretics $^{\S}$

Anticholesterol agents

Psychotropic agents ${ }^{\S}$

Psychotropic agents for QT

prolongation $^{\S}$

Follow-up

Death or resuscitated ${ }^{\S}$

Cardiac death or resuscitated

Sudden cardiac death or resuscitated $^{\S}$

Non-sudden cardiac death

Non-cardiac death
Active

$114(25 \%)$

$168(37 \%)$

$138(31 \%)$

$29(7 \%)$

$30(7 \%)$

$161(36 \%)$

$4(2-7)$

$390(87 \%)$

$308(68 \%)$

$103(23 \%)$

$121(27 \%)$

$412(92 \%)$

$14(3 \%)$

$11(2 \%)$
$1.5)^{*}$

$\begin{array}{ccc}79(17 \%) & 74(14 \%) & 52(11 \%) \\ & & \\ 180(39 \%) & 196(36 \%) & 162(34 \%) \\ 159(35 \%) & 209(39 \%) & 188(40 \%) \\ 40(9 \%) & 62(12 \%) & 72(15 \%) \\ 35(8 \%) & 42(8 \%) & 57(12 \%)^{*} \\ 163(36 \%) & 184(34 \%) & 167(35 \%) \\ 3(2-6) & 5(3-10) \dagger & 4(2-10) \dagger \\ 399(87 \%) & 479(88 \%) & 424(89 \%) \\ 302(66 \%) & 369(68 \%) & 341(72 \%) \\ 102(22 \%) & 136(25 \%) & 128(27 \%) \\ 151(33 \%) & 190(35 \%)^{*} & 200(42 \%)^{* \dagger} \\ 422(92 \%) & 497(92 \%) & 430(90 \%) \\ 24(5 \%) & 53(10 \%)^{* \dagger} & 63(13 \%)^{* \dagger} \\ 18(4 \%) & 41(8 \%)^{*} & 53(11 \%)^{* \dagger} \\ & & \\ 46(10.0 \%) & 57(10.5 \%) & 67(14.0 \%)^{*} \\ 18(3.9 \%) & 30(5.5 \%) & 33(6.9 \%) \\ 9(2.0 \%) & 14(2.6 \%) & 21(4.4 \%)^{*}\end{array}$

$\begin{array}{cccc}32(7.1 \%) & 46(10.0 \%) & 57(10.5 \%) & 67(14.0 \%)^{*} \\ 16(3.6 \%) & 18(3.9 \%) & 30(5.5 \%) & 33(6.9 \%) \\ 5(1.1 \%) & 9(2.0 \%) & 14(2.6 \%) & 21(4.4 \%)^{*}\end{array}$

$11(2.4 \%)>9(2.0 \%) \quad 16(3.0 \%) \quad 12(2.5 \%)$

$16(3.6 \%) \quad 28(6.1 \%) \quad 27(5.0 \%) \quad 34(7.1 \%)$

Values are mean (SD), median $\left(1^{\text {st }}-3^{\text {rd }}\right.$ quartile) or $\mathrm{n}(\%$ within group). CCS Canadian

Cardiovascular Society grading of angina pectoris, E/é ratio between early mitral inflow velocity and mitral annular early diastolic velocity, $A C E$ angiotensin converting enzyme, $A T I I$ angiotensin receptor II, *p<0.05 vs. $1^{\text {st }}$ DEPS-quartile, $\dagger p<0.05$ vs. $2^{\text {nd }}$ DEPS-quartile, $\ddagger p<0.05$ vs. $3^{\text {rd }}$ DEPS-quartile and $\$ p<0.05$ for the main effect of DEPS-quartiles. 
Table 2. The distribution of individual questions of DEPS for sudden cardiac deaths and for alive patients including all deaths except sudden cardiac deaths patients.

\begin{tabular}{|c|c|c|c|c|}
\hline & & Others & $\begin{array}{l}\text { Sudden } \\
\text { cardiac } \\
\text { death } \\
n=49\end{array}$ & $\bar{p}$ Value \\
\hline \multirow{4}{*}{$\begin{array}{l}\text { 1. Suffered from insomnia } \\
\operatorname{AUC}_{\mathrm{ROC}}(95 \% \mathrm{CI})=0.506(0.422-0.590), \mathrm{p}=0.89\end{array}$} & Not at all & $787(42 \%)$ & $21(43 \%)$ & \multirow[t]{4}{*}{0.64} \\
\hline & A little & $822(44 \%)$ & $19(40 \%)$ & \\
\hline & Quite a lot & $208(11 \%)$ & $8(17 \%)$ & \\
\hline & Extremely & $62(3 \%)$ & $1(2 \%)$ & \\
\hline 2. Felt blue & Not at all & $978(52 \%)$ & $21(44 \%)$ & \multirow[t]{4}{*}{0.07} \\
\hline \multirow{3}{*}{$\operatorname{AUC}_{\mathrm{ROC}}(95 \% \mathrm{CI})=0.527(0.451-0.603), \mathrm{p}=0.52$} & A little & $775(41 \%)$ & $28(57 \%)$ & \\
\hline & Quite a lot & $\left.97(5 \%)\right|^{3}$ & $0(0 \%)$ & \\
\hline & Extremely & $29(2 \%)$ & $0(0 \%)$ & \\
\hline \multirow{4}{*}{$\begin{array}{l}\text { 3. Felt that everything was an effort } \\
\operatorname{AUC}_{\mathrm{ROC}}(95 \% \mathrm{CI})=0.646(0.575-0.718), \mathrm{p}<0.001\end{array}$} & Not at all & $793(42 \%)$ & $8(17 \%)$ & \multirow[t]{4}{*}{$<0.001$} \\
\hline & A little & $807(43 \%)$ & $27(55 \%)$ & \\
\hline & Quite a lot & $232(12 \%)$ & $14(29 \%)$ & \\
\hline & Extremely & $47(3 \%)$ & $0(0 \%)$ & \\
\hline \multirow{4}{*}{$\begin{array}{l}\text { 4. Felt low in energy or slowed down } \\
\operatorname{AUC}_{\mathrm{ROC}}(95 \% \mathrm{CI})=0.584(0.506-0.662), \mathrm{p}=0.044\end{array}$} & Not at all & $738(39 \%)$ & $12(25 \%)$ & \multirow[t]{4}{*}{0.032} \\
\hline & A little & $838(45 \%)$ & $25(51 \%)$ & \\
\hline & & $251(13 \%)$ & $12(25 \%)$ & \\
\hline & & $52(3 \%)$ & $0(0 \%)$ & \\
\hline \multirow{4}{*}{$\begin{array}{l}\text { 5. Felt lonely } \\
\operatorname{AUC}_{\mathrm{ROC}}(95 \% \mathrm{CI})=0.528(0.442-0.614), \mathrm{p}=0.50\end{array}$} & Not at all & $1334(71 \%)$ & $33(67 \%)$ & \multirow[t]{4}{*}{0.09} \\
\hline & A little & $426(23 \%)$ & $9(18 \%)$ & \\
\hline & Quite a lot & $86(5 \%)$ & $6(12 \%)$ & \\
\hline & Extremely & $33(2 \%)$ & $1(2 \%)$ & \\
\hline \multirow{4}{*}{$\begin{array}{l}\text { 6. Felt hopeless about the future } \\
\text { AUC }_{\text {ROC }}(95 \% \mathrm{CI})=0.529(0.446-0.613), \mathrm{p}=0.48\end{array}$} & Not at all & $1254(67 \%)$ & $30(61 \%)$ & \multirow[t]{4}{*}{0.85} \\
\hline & A little & $510(27 \%)$ & $15(31 \%)$ & \\
\hline & Quite a lot & $90(5 \%)$ & $3(6 \%)$ & \\
\hline & Extremely & $25(1 \%)$ & $1(2 \%)$ & \\
\hline 7. Not got any fun of lif & Not at all & $1260(67 \%)$ & $30(61 \%)$ & \multirow[t]{4}{*}{0.30} \\
\hline \multirow{3}{*}{$\operatorname{AUC}_{\mathrm{ROC}}(95 \% \mathrm{CI})=0.520(0.440-0.600), \mathrm{p}=0.633$} & A little & $499(27 \%)$ & $18(37 \%)$ & \\
\hline & Quite a lot & $90(5 \%)$ & $1(2 \%)$ & \\
\hline & Extremely & $30(2 \%)$ & $0(0 \%)$ & \\
\hline \multirow{4}{*}{$\begin{array}{l}\text { 8. Had feelings of worthlessness } \\
\operatorname{AUC}_{\mathrm{ROC}}(95 \% \mathrm{CI})=0.588(0.504-0.672), \mathrm{p}=0.035\end{array}$} & Not at all & $1366(73 \%)$ & $27(55 \%)$ & \multirow[t]{4}{*}{0.032} \\
\hline & A little & $416(22 \%)$ & $18(37 \%)$ & \\
\hline & Quite a lot & $70(4 \%)$ & $2(4 \%)$ & \\
\hline & Extremely & $27(1 \%)$ & $2(4 \%)$ & \\
\hline \multirow{4}{*}{$\begin{array}{l}\text { 9. Felt all pleasure and joy has gone from life } \\
\operatorname{AUC}_{\text {ROC }}(95 \% \mathrm{CI})=0.558(0.474-0.642), \mathrm{p}=0.16\end{array}$} & Not at all & $1288(69 \%)$ & $28(57 \%)$ & \multirow[t]{4}{*}{0.19} \\
\hline & A little & $466(25 \%)$ & $16(33 \%)$ & \\
\hline & Quite a lot & $101(5 \%)$ & $5(10 \%)$ & \\
\hline & Extremely & $24(1 \%)$ & $0(0 \%)$ & \\
\hline 10. Felt that I cannot shake off the blues even with & Not at all & $1422(76 \%)$ & $31(63 \%)$ & 0.09 \\
\hline
\end{tabular}




\begin{tabular}{|c|c|c|c|c|}
\hline $\operatorname{AUC}_{\mathrm{ROC}}(95 \% \mathrm{CI})=0.564(0.479-0.650), \mathrm{p}=0.12$ & $\begin{array}{c}\text { A little } \\
\text { Quite a lot } \\
\text { Extremely }\end{array}$ & $\begin{array}{l}348(19 \%) \\
89(5 \%) \\
20(1 \%)\end{array}$ & $\begin{array}{l}13(27 \%) \\
3(6 \%) \\
2(4 \%)\end{array}$ & \\
\hline $\begin{array}{l}\text { Depression Scale Score } \\
\text { AUC }_{\text {ROC }}(95 \% C I)=0.618(0.543-0.693), p=0.005\end{array}$ & & $4(2-7)$ & $5(2-10)$ & 0.005 \\
\hline $\begin{array}{l}\text { Depression Scale Score (quartiles) } \\
\operatorname{AUC}_{\text {ROC }}(95 \% C I)=0.630(0.554-0.707), p=0.002\end{array}$ & $\begin{array}{l}1^{s t} \\
2^{\text {nd }} \\
3 r d \\
4 t h\end{array}$ & $\begin{array}{l}445(24 \%) \\
450(24 \%) \\
528(28 \%) \\
456(24 \%)\end{array}$ & $\begin{array}{l}5(10 \%) \\
9(18 \%) \\
14(29 \%) \\
21(44 \%)\end{array}$ & 0.012 \\
\hline
\end{tabular}

Values are number (proportion) of patients or median $\left(1^{\mathrm{st}}-3^{\text {rd }}\right.$ quartile). $\mathrm{AUC}_{\mathrm{ROC}}=$ area under the receiver operating characteristic curve, $\mathrm{CI}=$ confidence interval 
Table 3. Cox regression analysis for Depression Scale answers which were associated with sudden cardiac death.

All-cause mortality Sudden cardiac death

\begin{tabular}{|c|c|c|}
\hline & $\mathrm{n}=\mathbf{2 0 2}$ & $n=49$ \\
\hline Univariate & $\begin{array}{c}\text { Hazard ratio } \\
\text { (95\% CI })\end{array}$ & Hazard ratio \\
\hline 3. Felt everything was an effort $\geq A$ little & $1.6(1.2-2.1) \dagger$ & \\
\hline 4. Felt low in energy or slowed down $\geq$ A little & $1.5(1$ & $2.0(1.0-3.8)^{*}$ \\
\hline 8. Had feelings of worthlessness $\geq$ A little & & $2.1(1.2-3.7) \dagger$ \\
\hline Depression Scale Score (quartiles) $4^{\text {th }}$ vs. $1^{\text {st }}$ & $\dagger$ & $4.0(1.5-10.5) \dagger$ \\
\hline $2^{\text {nd }}$ & $1.5(1.0-2.1)$ & $2.3(1.1-5.1)^{*}$ \\
\hline $3^{r d}$ & 4) & $1.7(0.9-3.4)$ \\
\hline $1^{\text {st }}-3^{\text {rd }}$ & $1.5(1.2-2.1) \dagger$ & $2.3(1.3-4.1) \dagger$ \\
\hline Multivaria & & \\
\hline 3. Felt & $1.4(1.0-1.9)^{*}$ & $3.5(1.5-7.9) \dagger$ \\
\hline 4. Felt low in energy or slowed down $\geq$ A little & $1.5(1.1-2.0)^{*}$ & $1.7(0.9-3.5)$ \\
\hline 8. Had feelings of worthlessness $\geq$ A little & $1.3(0.9-1.7)$ & $1.9(1.1-3.5)^{*}$ \\
\hline Depression Scale Score (quartiles) $4^{\text {th }}$ vs. $1^{s t}$ & $1.8(1.1-2.8)^{*}$ & $3.2(1.2-8.9)^{*}$ \\
\hline $2^{\text {nd }}$ & $1.4(0.9-2.0)$ & $2.1(0.9-5.0)$ \\
\hline & $1.4(0.9-2.0)$ & $1.9(0.9-3.9)$ \\
\hline $1^{\text {st }}-3^{\text {rd }}$ & $1.4(1.1-2.0)^{*}$ & $2.2(1.2-4.0) \dagger$ \\
\hline
\end{tabular}

$\overline{\mathrm{CI}}=$ confidence interval. Multivariate analysis adjusted for age, sex, body mass index, type 2 diabetes, Canadian Cardiovascular Society grading of angina pectoris, left ventricular ejection 
fraction, the use of psychotropic medication and leisure-time physical activity. 80 patients excluded from the analysis because of missing values (including 8 deaths and 3 SCDs). ${ }^{*} \mathrm{p}<0.05$ and $\uparrow \mathrm{p}<0.01$. 